\title{
ISOLATION AND CHARACTERIZATION OF A NOVEL BENZOATE- UTILIZING Serratia marcescens
}

\author{
DWI SURYANTO ${ }^{1}$ and ANTONIUS SUWANTO ${ }^{2,3 *}$ \\ 'Department of Biology, Faculty of Mathematics and Natural Sciences, \\ North Sumatra University, Medan, Indonesia \\ . Department of Biology, Faculty of Science and Mathematics, \\ Bogor Agricultural University, Bogor, Indonesia \\ ${ }^{3}$ SEAMEO-BIOTROP, P.O. Box. 116, Bogor, Indonesia
}

\begin{abstract}
A new benzoate-utilizing strain, Serratia marcescens DS-8, isolated from the environment was characterized. The strain was enterobacilli, Gram negative, mesophilic, non halophilic, and aerobic bacterium that showed motile ovalerod shaped cells. The isolate produced extracellular chitinase, protease, and prodigiosin (a red pigment produced by several Serratia strains yielding bright red or pink colonies). A physiological assay using Microbact* test showed that the strain was closely related to Klebsiella ozaenae (49.85\%) and Serratia liquefaciens (24.42\%), respectively. However, $16 \mathrm{~S}$ rRNA sequence analysis indicated that the strain was closely related to $S$. marcescens DSM 30121 with similarity level of $98 \%$. DS-8 strain was able to synthesize its own vitamins. Optimum growth in benzoate was obtained at $\mathrm{pH}$ between 7-8.5 and $\mathrm{NaCl}$ concentration of 1-1.5\% (w/v). The isolate could grow in benzoate-containing medium up to $10 \mathrm{mM}$. Other carbon sources that could support the growth of DS-8 were casamino acid, glutamate, glucose, acetate, potato starch, and ethanol.
\end{abstract}

Keywords: Serratia marcescens/aromatic degradation/168 rRNA sequence

\section{INTRODUCTION}

A large amount of monocyclic hydrocarbon aromatic and its derivatives, as well as polycyclic hydrocarbon aromatic, have been deliberately introduced to the environment. Many of these compounds, particularly the chlorinated derivatives, are toxic and carcinogenic even at low concentrations.

The metabolism of these hydrocarbon aromatic compounds in nature depends on the ability of catabolic reaction of particular microorganisms (Semple and Cain 1996). Of these microorganisms, bacteria of the genera such as Alcaligenes, Bacillus, Pseudotnonas, Bulkholderia, and Rhodococcus (Guerin and Boyd 1995; Lenke et al. 1992; Mars et al. 1996; Shen and Wang 1995) are the main degrading microbes. Several other microorganisms such as fungus (Gurujeyalakshmi and Oreil 1989), and algae (Semple and Cain 1996) have also been reported to aerobically catabolize aromatic hydrocarbons.

One of the important monocyclic aromatics introduced to the environment is benzoate. It has been introduced through some herbicides application or other industrial

'Corresponding author, E-mail: asuwanto@indo.net.id 
practices (Werwath et al. 1998). Hence, it is also found as one of the important intermediate in metabolic pathway of many aromatic compounds (Powlowski and Shingler 1994). The increasing need of this aromatic compound for industrial purposes and its application should make us aware of its environmental potential hazard. So far, a study on aerobic benzoatc and its derivative degradation has been done in Acinetobacter sp. strain 4CB1 (Adriaens et al. 1989), Amycolatopsis and Streptomyces spp. (Grund et al. 1990), and Pseudomonas (Altenschmidt et al. 1993). In the group of Enterobacteriaceae, Klebsiella pneumonia was reported to degrade 3- and 4-hydroxy-benzoate (Suarez et al. 1991), and Salmonella typhimurium was able to metabolize $m$-hydroxybenzoate and gentisate (Goetz et al. 1992). Diaz et al. (2001) noted the involvement of Escherichia coli in the metabolism of phenylacetic acid, 3- and 4-hydroxyphenylacetic acid, phenylpropionic acid, 3hydroxyphcnylpropionic acid, and 3-hydroxycinnamic acid and amines (phenylethylamine, tyramine, and dopamine).

In this study, another member of Enterobacteriaceae, Serratia marcescens strain DS-8 was found capable of using benzoate as its sole C-source. We would like to examine further the ability of S. marcescens DS-8 to utilize benzoate and to characterize its physiological properties as well as its taxonomic identity.

\section{MATERIALS AND METHODS}

\section{Bacterial isolate and culture condition}

The isolate was previously isolated from household sewage water in Bogor, West Java, Indonesia. Screening was carried out by growing the isolate in modified salt medium (Dong et al. 1992) supplemented with $5 \mathrm{mM}$ Na-benzoate as sole carbon source. The isolate was maintained in $12.5 \%$ glycerol at $-70^{\circ} \mathrm{C}$.

\section{Benzoate and other $C$ source utilization test}

Benzoate utilization was determined by growing the isolate in a modified salt medium supplemented with or without vitamins with $5 \mathrm{mM}$ Na-benzoatc as a carbon source. Escherichia coli TOP 10 was used as a control. To determine the degrading ability in different conditions, the isolate was grown in modified salt medium with different initial $\mathrm{pH}, \mathrm{NaCl}$ concentration, and benzoate concentration. Growth in other $\mathrm{C}$ sources was performed in modified salt medium supplemented with vitamins with either $5 \mathrm{mM}$ succinate, $5 \mathrm{mM}$ glucose, $1 \%$ casamino, $5 \mathrm{mM}$ citrate, $5 \mathrm{mM}$ glutamate, $5 \mathrm{mM}$ acetate, $3 \%$ ethanol, or $1 \%$ potato starch as carbon sources. Cell, density in other $\mathrm{C}$ source utilization test and benzoate utilization test were measured turbidimetrically at $660 \mathrm{~nm}$ after 72 hours and 120 hours of incubation time, respectively. 
Benzoate-utilizing Serratia marcescens — Dwi Suryanto \& Antonius Suwanto

\section{Growth conditions, measurement of growth, and quantification of benzoate utilization}

All liquid cultures were cultivated aerobically in $250 \mathrm{ml}$ Erlenmeyer. Cultures were grown in $200 \mathrm{rpm}$ at $30^{\circ} \mathrm{C}$. Growth was measured turbidimetrically at $660 \mathrm{~nm}$. Benzoate concentration was measured at its absorption maximum of $276 \mathrm{~nm}$ using Hitachi Model U-2010 UV/Vis spectrophotometer (Hitachi Instrument, Inc. Japan) following the establishment of standard curve relating benzoate concentration to UV absorbance (Shoreit and Shabeb 1994).

For all inoculations, the seed cultures were taken from 2-day-old culture of modified salt medium with $5 \mathrm{mM}$ Na-benzoate as carbon source. The cultures were grown with the initial cell concentration of $5 \times 10^{6}$ cell $/ \mathrm{ml}$. Unless otherwise indicated, all media were adjusted to $\mathrm{pH} 7.2$. Benzoate solution was filter-sterilized.

\section{Examination of cell morphology and physiological properties}

Cell shape, motility, and Gram staining were evaluated using a Nikon YS2-T microscope. Physiological characteristics were analyzed using Microbact kit test (Medvet Science Pty. Ltd., Adelaide, Australia). Test of production of extracellular protease and chitinase was monitored on salt medium agar supplemented with colloidal chitin and skim milk. EMB agar was used for preliminary screening for Enterobacteriaceae isolates. The appearance of the colonies was observed in Luria Bertani (LB) agar supplemented with either 50 (-ig/ml ampicillin, $50 \mathrm{ng} / \mathrm{ml}$ spectinomycin/streptomycin, $10 \mathrm{ng} / \mathrm{ml}$ trimethoprim, $5 \mathrm{mM}$ benzoate, $5 \mathrm{mM}$ salycilate, $5 \mathrm{mM}$ gentisate, or $5 \mathrm{mM}$ phenol. A test of growth in different temperatures was monitored on LB agar.

\section{Amplification and sequencing of part of 16S rRNA gene}

The 16S-rRNA genes were PCR-amplified using specific primers of $63 \mathrm{f}$ and $1387 \mathrm{r}$ from genomic DNA (200 ng) using Ready-To-Go PCR Beads (Pharmacia-Biotech). Modified phenolchloroform-isoamylalcohol treatment, ethanol precipitation, and agarose gel electrophoresis were used to purify the genomic DNA. The total volume of PCR reactions (25|il) consisted of $1.5 \mathrm{U}$ Taq DNA Polymerase, lOmM Tris-HCl (pH 9 at room temperature), $50 \mathrm{mM} \mathrm{KC1,} 1.5 \mathrm{mM} \mathrm{MgCl}$, $200 \mid M$ of each dNTPs, and stabilizer including bovine serum albumin. The reaction was incubated in a Gene Amp PCR System 2,400 Thermocycler (Perkin-Elmer Cetus, Norwalk, Conn).

Part of the genes for 16S-rRNA were sequenced to infer the closest related organism from Ribosomal Database Project (RDP) maintained in the University of Illinois, Urbana-Champaign. The sequencing reactions were done by using the Big Dye Ready Reaction Dye Deoxy Terminator kit and purification with ethanol- 
sodium acetate precipitation. The reactions were run on an ABI PRISM 377 DNA Sequencer (Perkin-Elmer Cetus, Norwalk, Conn.).

\section{Construction of phylogenic tree}

Cluster analysis of 16S-rRNA gene was done using the computer program from European Bioinformatics Institute (http://www.ebi.ac.uk). The treecon computer program (Yves Van de Peer of Department of Biochemistry, University of Antwerp) was used to determine the relatedness in phylogenic tree based on the nucleotide sequences.

\section{RESULTS AND DISCUSSION}

The new benzoate-utilizing bacteria, DS-8, described in this study was a motile, ovale-rod shaped, Gram negative, mesophilic, non halophilic, and aerobic bacterium. Instead of microscope observation, the motility could be seen by its swarming activity. On LB solidified with $1.2 \%$ agar, the strain swarm on the agar surface, colonized the entire plate with expansion rate of c.a. 19 $\mathrm{mm} /$ hours. Eberl et al. (1999) also observed a similar behavior in S. liquefaciens MG1. An auto-induction phenomenon might be involved in this swarming activity (Eberl et al. 1999; Lindumefa/. 1998).

Based upon Microbact test (Table 1), DS-8 was closely related to K. ozaenae (49.85\%) and S. liquefaciens (24.42\%), respectively. However, the test might have no significant match to the available characteristics in Microbact data of bacterial species. This might occur since the test is designed for hospital purposes. Any other specific characters for isolates might not be incorporated in this detection kit. Growth on EMB media indicated that the isolate was a member of Enterobacteriaceae. Partial sequencing (c.a. 500 bp of the 5'-end) of 16S rRNA gene of DS-8 showed that the isolate might likely be one species of S. marcescens DSM 30121 (98\% of similarity) (Figure 1). The isolate showed lower similarity (94\%) to strain K. ozaenae. Complete sequencing of the 16S rRNA gene, however, should give more definitive information about the taxonomic position of the isolate.

The isolate produced a red or pink pigmentation on LB agar, or on LB agar supplemented with ampicillin, and streptomycin and spectinomycin, trimethoprim, tetracyclin, skim milk, or chitin (Table 2). On the former antibiotic-containing media, the pink color appeared later in the growth stage. No red or pink color was produced when grown in media containing $1 \mathrm{mM}$ phenol, 5 $\mathrm{mM}$ salycilate, $5 \mathrm{mM}$ gentisate, or in LB agar supplemented with gentamicin. The red pigment might be prodigiosin, a red pigment produced by the genus of Serratia. We did not examine whether the media affected the prodigiosin production, or a quorum sensing might take an effect. Other interesting physiological traits were that the isolate produced extracellular chitinase and protease. A study on genetic and cloning of gene encoding chitinase of $S$. marcescens has been done by Watanabe et al. (1997). 
Benzoate-utilizing Serratia marcescens — Dwi Suryanto \& Antonius Suwanto

Table 1. Physiological and biochemical characterization of DS- 8 based on Microbact test

\begin{tabular}{cccc}
\hline \hline Test & Reaction & Test & Reaction \\
\hline Oxygenase & - & Citrate & + \\
Motility & + & TDA & + \\
Nitrate & + & Gelatine & - \\
Lysine & + & Malonate & - \\
Ornithine & + & Inositol & + \\
H $\mathrm{S}$ & - & Sorbitol & + \\
Glucose & + & Rhamnose & + \\
Mannitol & + & Sucrose & + \\
Xylose & + & Lactose & + \\
ONPG & + & Arabinose & + \\
Indole & - & Adonitol & + \\
Urease & - & Rafinose & + \\
V.P. & - & Salisine & - \\
EMB & + & Arginine & + \\
Chitinase & + & Protease & + \\
3\% KOH & - & Katalase & + \\
Gram & - & Temperature & $20-35^{\circ} \mathrm{C}$ \\
\hline
\end{tabular}

Table 2. The appearance of DS-8 colonies when grown on different media

\begin{tabular}{lcc}
\hline \multicolumn{1}{c}{ Media } & Colony color & Growth \\
\hline LB agar & Red & +++ \\
LB agar $50 \mu \mathrm{g} / \mathrm{ml}$ ampicillin & Red & +++ \\
LB agar $+50 \mu \mathrm{g} / \mathrm{ml}$ spectinomycin/streptomycin & Pink/white & +++ \\
LB agar $+20 \mu \mathrm{g} / \mathrm{ml}$ gentamycin & White & ++ \\
LB agar $+10 \mu \mathrm{g} / \mathrm{ml}$ tetracyclin & Pink & ++ \\
LB agar+10 $\mu \mathrm{g} / \mathrm{ml}$ trimethoprim & White & ++ \\
Chitin & Pale pink & +++ \\
Skim milk & Red & ++ \\
$5 \mathrm{mM}$ benzoate & Pink & ++ \\
$5 \mathrm{mM}$ salycilate & White & ++ \\
$5 \mathrm{mM}$ gentisate & White & + \\
mM phenol & Pink & ++ \\
\hline
\end{tabular}

The ability of the isolate to grow on structurally similar aromatic compounds like benzoate, gentisate, salycilate, and phenol, can be explained as it might have similar cell membrane transport system or similar catabolic pathway after ring fission (Shimp and Pfaender 1987). The different ability to grow in benzoate, gentisate, salycilate, and phenol (Table 2) might be due to different uptake efficiency (Altenschmidt et al. 1993).

DS-8 was able to grow aerobically in $5 \mathrm{mM}$ benzoate with or without vitamin supplement (Figure 2). However, different responses of growth in these media were 


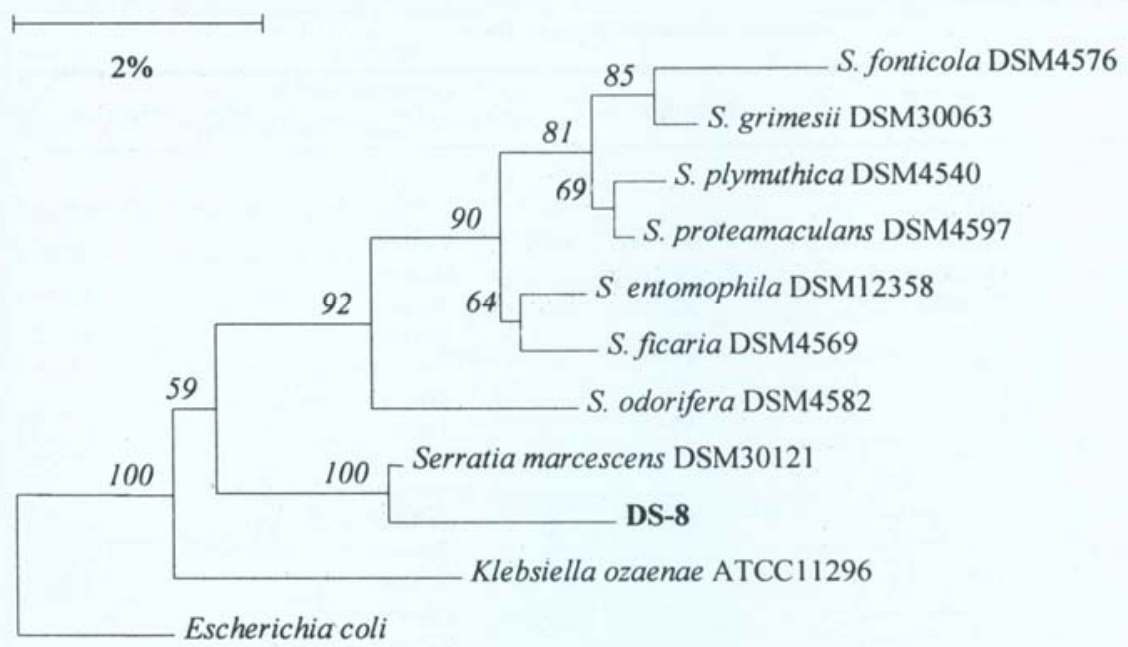

Figure 1. Dendrogram of DS-8 and its relatives.

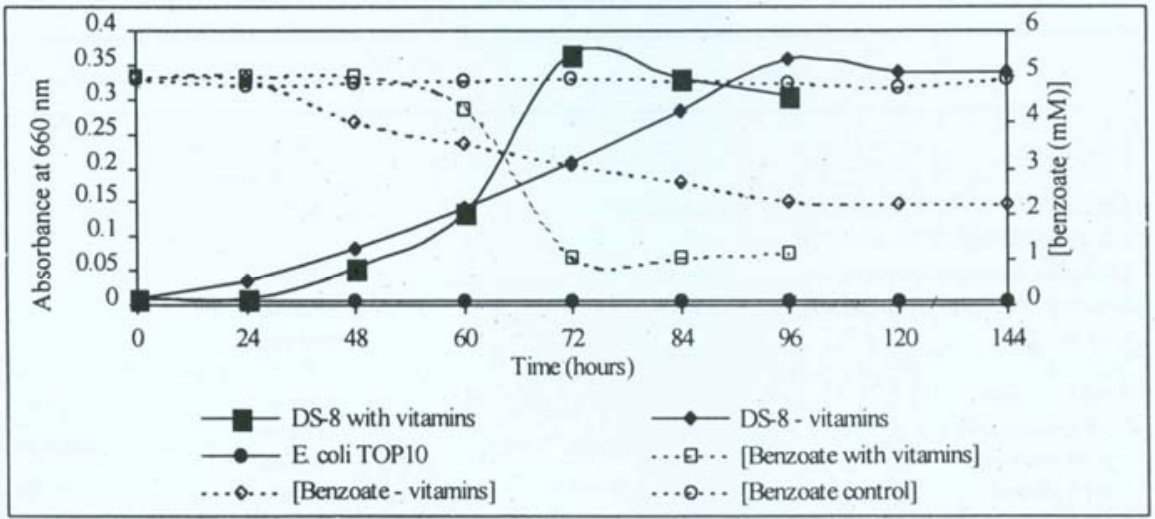

Figure 2. Growth of DS-8 (straight line) and benzoate utilization (dotted line) in benzoate medium supplemented with vitamins and without vitamins. E. coli TOP10 was employed as a control of benzoate utilization.

significant. Bacterial growth in media supplemented with vitamins was faster than they were without vitamins. DS-8 clearly required vitamins for optimal growth in benzoate. The generation time in media with vitamins and media without vitamins were 11.4 hours and 16.8 hours, respectively. Consequently, benzoate degradation also occurred much faster in media supplemented with vitamins. In media with 
vitamin supplementation, benzoate utilization rate was $0.16 \mathrm{mM} /$ hour compared to $0.04 \mathrm{mM} / \mathrm{hour}$ in media without vitamin supplement.

The ability to grow in the aromatic compound without vitamins indicated that the isolate was capable of synthesizing its own vitamins. Relatively low cell density (absorbance at $660 \mathrm{~nm}$ ) in this study might be a result of using poor media ( Figure 3A). Minimal media for this purpose are usually supplemented with $0.01 \%$ yeast extract or other common C sources (Adriaens et al. 1989; Gurujeyalakshmi and Oriel 1989; Shimao et al. 1989).

As shown in Figure 3, optimum $\mathrm{pH}$ and $\mathrm{NaCl}$ concentration for bacterial growth was between 7-8.5 and 1-1.5\%, respectively. The optimum range of $\mathrm{pH}$ and $\mathrm{NaCl}$ concentrations showed that the isolate was not acidophilic or halophilic. Optimum growth temperature was in the range of $20-35^{\circ} \mathrm{C}$. This isolate could not grow at $40^{\circ} \mathrm{C}$. At $37^{\circ} \mathrm{C}$, no red pigment appeared. Andreeva and Ogorodnikova (1999) observed that prodigiosin was not accumulated by growing $S$. marcescens at this temperature.

DS-8 grew very poorly in media with benzoate concentration exceeding $10 \mathrm{mM}$. A common concentration for benzoate degradation test was up to $5 \mathrm{mM}$ (Altenschmidl et al. 1993; Bundy et al. 1998). An increase in cell tolerance against toxic substrates was crucial to improve the degradation capabilities. Alteration of CM to trans-fatty acid of cell membrane might improve cell tolerance to toxic substrates (Heipieper et al. 1992). Relatively poor growth of the isolate was also observed in $5 \mathrm{mM}$ benzoate without vitamin supplement. Hence, vitamins were needed for optimum growth. Benzoate utilization might indirectly depend on $\mathrm{pH}, \mathrm{NaCl}$ concentration, as well as benzoate concentration, since the cell growth was affected by initial $\mathrm{pH}$, $\mathrm{NaCl}$ concentration, and benzoate concentration (Figure 3).

The experiment with other organic compounds showed that the isolate grew well in media with casamino acid and glutamate (Figure 4). The isolate grew poorly in glucose, acetate, potato starch, and ethanol and failed to grow in succinate or citrate. It seemed that the availability of organic nitrogen in casamino acid and glutamate supported the growth of DS-8. Eberl et al. (1999) showed that the doubling time of S. liquefaciens MG1 was significantly increased even in only $0.01 \%$ casamino acid. The inability of DS-8 to utilize succinate and citrate might be due to the lack of special transport system. For example, an inducible transport system for malate, succinate, and fumarate was present in Rhodobacter (Rhodop-seudomonas) sphaeroides (Gibson 1975).

\section{ACKNOWLEDGEMENTS}

This research was funded by the Center for Microbial Diversity, Faculty of Science and Mathematics, Bogor Agricultural University, Bogor, Indonesia. 

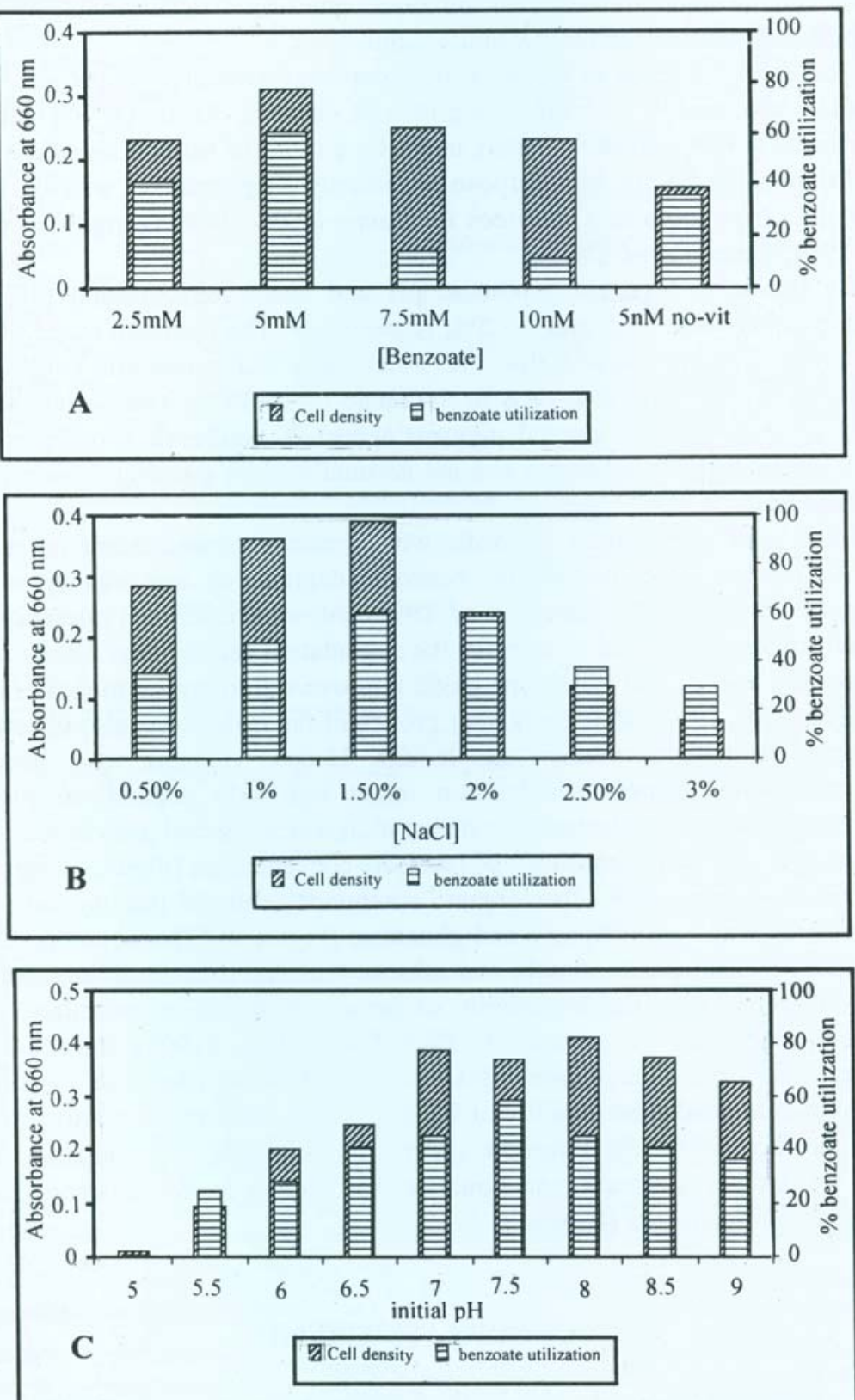

Figure 3. Profiles of growth of DS-8 and benzoate degradation in different benzoate concentration (A), $\mathrm{NaCl}$ concentration (B), and different initial $\mathrm{pH}(\mathrm{C})$. 


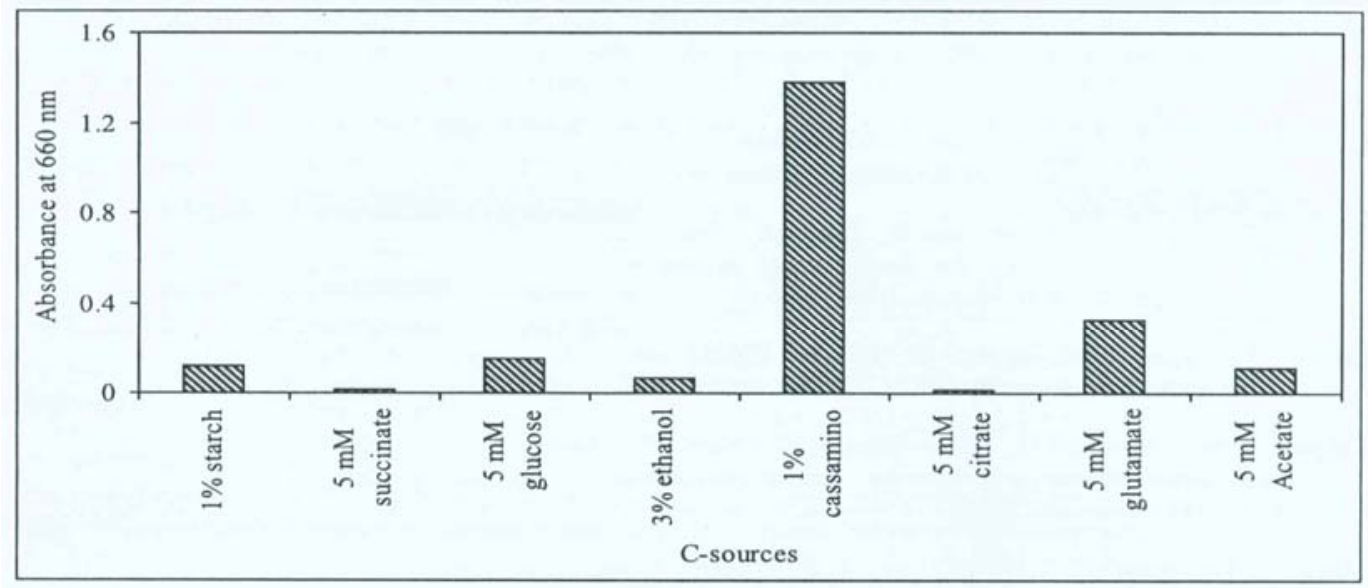

Figure 4. Growth of DS-8 in different C-sources. The media were supplemented with vitamins.

\section{REFERENCES}

Adriaens, P., Kohler, H-PE., Kohler-Staub, D., and D.D. Focht. 1989. Bacterial dehalogenation of chlorobenzoate and coculture biodegradation of 4,4'-dichlorobiphenyl. Appl. Environ. Microbiol., 55, 887-892.

Andreeva, I.N. and T.I. Ogorodnikova. 1999. The effect of the cultivation conditions on the growth and pigmentation on Serratia marcescens. Zh. Mikrobiol. Epidemiol. Immunobiol., 3,16-20. (Abstract).

Altenschmidt, U., Oswald, B., Steiner, E., Herrmann, H., and G. Fuchs. 1993. New aerobic benzoate oxidation pathway via benzoyl-coenzyme A and 3-hydroxybenzoyl-coenzyme A in a denitrifying Pseudomonas sp. J. Bacteriol. 175,48514858 .

Bundy, B.M., Campbell, A.L., and E.L. Neidle. 1998. Similarities between the ont4SC-encoded anthranilate dioxygenase and the ie«^5C-encoded benzoate dioxygenase of Acinetobacter sp. strain ADP1. J. Bacteriol. 180, 4466-4474.

Eduardo Diaz, E., Ferrandez, A., Prieto, M.A., and J.L. Garcia. 2001. Biodegradation of Aromatic Compounds by Escherichia coli. Microbiol. Mol. Biol. Rev. 65, 523-569.

Dong, F., Wang, L., Wang, C., Cheng, J., He, Z.,.Sheng, Z., and R. Shen. 1992. Molecular cloning and mapping of phenol degradation genes from Bacillus stearothermophilus FDTP-3 and their expression in Escherichia coli. Appl. Environ. Microbiol. 58,2531-2535.

Eberl, L., Molin, S., and M. Givkov. 1999. Surface motility of Serratia liquefaciens MG1. J. Bacteriol. 181,1703-1712.

Gibson, J. 1975. Uptake of C4 dicarboxylates and pyruvate by Rhodopseudomonas sphaeroides. J. Bacteriol. 123,471480.

Grund. E., Knorr, C., and R. Eichenlaub. 1990. Catabolism of benzoate and monohydroxylated benzoates by Amycolatopsis and Streptomyces spp. Appl. Environ. Microbiol. 56,1459-1464. 
Guerin, W.F. and S.A. Boyd. 1995. Maintenance and induction of naphthalene degradation activity in Pseudomonas putida and an Alcaligenes sp. under diiferent culture conditions. Appl. Environ. Microbiol. 6, 4061-4068.

Gurujeyalakshmi, G. and P. Oriel. 1989. Isolation of phenol-degrading Bacillus stearothermophi/us and partial characterization of the phenol hydroxylase. Appl. Environ. Microbiol. 55,500-502.

Hiepieper, H.J., Diefenbach, R., and H. Kuweloh. 1992. Conversion of cis-unsaturated fatty acids to trans, a possible mechanism for the protection of phenol-degrading Pseudomonas putida P8 from substrate toxicity. Appl. Environ. Microbiol. 58,18471852.

Lenke, H., Pieper, D.H., Bruhn, C., and H. Knackmuss. 1992. Degradation of 2,4-dinitrophenol by two Rhodococcus erythropolis strains, HL 24-1 andHL 24-2. Appl. Environ. Microbiol. 58,2928-2932.

Lindum, P.W., Anthoni, U., Christofferson, C., Eberl, L., Molin, S., and M. Givskov. 1998. Af-acyl-L-homoserine lactone autoinducers control production of an extracellular surface-active lipopeptide required for swarming motility ofSetratia liquefaciens MG1. J. Bacteriol. 180,6384-6388.

Mars, A., Houwing, J., Dolfmg, J., and D.B. Janssen. 1996. Degradation of toluene and trichloroethylene by Bulkholderia cepacia G4 in growth-limited fed-batch culture. Appl. Environ. Microbiol. 62, 886-891.

Powlowski, J. and V. Shingler. 1994. Genetics and biochemistry of phenol degradation by Pseudomonas sp. CF600. Biodegrad. 5,219-236

Semple, K.T. and R.B. Cain. 1996. Biodegradation of phenols by the alga Ochromonas danica. Appl. Environ. Microbiol. 62,1264-1273.

Shen, H and Y. Wang. 1995. Simultaneous chromium reduction and phenol degradation in a coculture of Escherichia coli ATCC 33456 and Pseudomonas putida DMP-1. Appl. Environ. Microbiol. 61, 2754-2758.

Shimao, M., Onishi, S.; Mizumori, S., Kato, N., and C. Sakazawa. 1989. Degradation of 4-chlorobenzoate by facultatively alkalophilic Arthrobacter sp. strain SB8. Appl. Environ. Microbiol. 55,478^182.

Shoreit, A.A.M. and M.S.A. Shaheb. 1994. Utilization of aromatic compounds by phototrophic purple nonsulfur bacteria. Biodegrad. 5,71-76.

Suarez, M., Gibello, A., Allende, J.L., Martin, M., Ferrer, E., and A. Girrido-Pertierre. 1991. Degradation of 3- and 4hydroxybenzoate by K/ebsiellapneumoniae. Appl. Microbiol. Biotechnol. 34,677-682.

Shimp, R.J. and F.K. Pfaender. 1987. Effect of adaptation to phenol on biodegradation of monosubstituted phenols by aquatic microbial communities. Appl. Environ. Microbiol. 53,1496-1499.

Watanabe, T., Kimura, K., Sumiya, T., Nikaidou, N., Suzuki, K., Suzuki, M., Taiyoji, M., Ferrer, S., and M. Regue. 1997. Genetic analysis of the chitinase system of Serratia marcescens 2170. J. Bacteriol. 179, 7111-7117.

Werwath, J., Arfrnann, H., Pieper, D.H., Timrnis, K.N., and R. Wittich. 1998. Biochemical and genetic characterization of a gentisate 1,2-dioxygenase from Sphingomonas sp. strain RW5. J. Bacteriol. 180,4171-4176. 